\title{
Energy-saving behaviour as a demand-side management strategy in the developing world: the case of Bangladesh
}

\author{
Imran Khan ${ }^{1,2}$ (D)
}

Received: 5 January 2019 / Accepted: 29 March 2019 / Published online: 10 April 2019

(c) The Author(s) 2019

\begin{abstract}
Although demand-side management (DSM) needs to be more customer centred, either with or without smart technologies (e.g. smart grid), less attention has been paid to the developing world in relation to DSM strategy development. The main reasons have been lack of appropriate technology and capital costs. Importantly, there are alternative DSM strategies that require minimum or no cost to implement and provide immediate results, of which energy-saving behaviour of the occupants at residences is one. This study explores the potentiality of this energy-saving behaviour as a DSM strategy for the least developed economies, focusing particularly on Bangladesh. The literature suggests that energy-saving behaviour could reduce energy demand by a maximum of $21.9 \%$. However, this potential DSM scheme seems underestimated in the national DSM programme of Bangladesh. The Energy Efficiency and Conservation Master Plan (EECMP) of Bangladesh (a DSM program) shows that efficiency improvement in the use of home appliances could reduce electricity demand in the residential sector by about $28.8 \%$, but this does require a long time to be implemented, whereas the inclusion of energy-saving behaviour as a demand response strategy in residences along with the EECMP might achieve demand reduction of up to 50.7\%. Although the findings from this study are specific to Bangladesh, these could be useful guidelines for the policymakers of other developing nations where national DSM strategy development is underway.
\end{abstract}

Keywords Energy-saving behaviour · Residential electricity consumption · Demand-side management $\cdot$ Demand response $\cdot$ Energy efficiency and conservation $\cdot$ Bangladesh

\section{Introduction}

To provide for economic growth, electricity demand continues to soar, particularly in the developing world, where about $72 \%$ of this growth was met by fossil fuels in 2017; notably, this growth contributed to increasing the world's energyrelated emissions by $1.4 \%$ in this year [1]. Meeting the peaks in demand is one of the reasons for this increased emission from electricity generation. Peak electricity demands are usually met by fossil fuel generations such as oil and gas; hence, peak demand hours are more carbon intensive than off-peak hours [2]. This indicates the need to reduce

Imran Khan

ikr_ece@yahoo.com; i.khan@just.edu.bd

1 Centre for Sustainability, University of Otago, Dunedin, New Zealand

2 Department of Electrical and Electronic Engineering, Jashore University of Science and Technology, Jashore, Bangladesh electricity demand, in particular peak demand, which has caught the attention of many recent studies [3-8].

Demand-side management (DSM) was found to be one of the most promising strategies in reducing peaks since the 1980s $[9,10]$. However, most studies considered DSM strategies in the developed world [11-14], due to the fact that making DSM more effective requires the latest technologies such as smart grid, including smart meters [12]. Nevertheless, deployment of appropriate DSM strategies is indispensable in the developing world as well, where frequent power cuts are a common phenomenon during hours of peak demand due to insufficient generation capacities [15]. Although it is true that DSM is a crucial strategy in reducing peaks in demand, much less attention has been paid to developing nations in relation to appropriate DSM strategy development. This study thus addresses this gap in the literature and discusses possible DSM strategies that might be useful in developing countries in reducing electricity demands, including peak demand. 


\section{DSM in developed and developing countries}

DSM offers benefits for both electricity providers (the supply side) and consumers (the demand side) at the same time [16]. For example, DSM ensures grid reliability and reduces operational costs for the former, while reducing electricity costs for the latter. Considering these benefits, most developed nations are adopting smart grid technologies to better implement DSM strategies [12, 17-20].

A large and growing body of recent literature has investigated DSM opportunities in the developed world [11, 20-25]. For example, a recent study in Germany proposed a model which is able to identify and quantify DSM potential for distributed energy supply systems [23]. Incentivebased demand response in a renewable microgrid system has been investigated considering the operational management opportunities in [26]. Alasseri et al. (2017) found that incentive-based DSM strategies were suitable for Kuwait [24]. Energy management opportunities through smart home technologies were investigated in [11] in the UK. Future demand response and its economic potential were investigated through a modelling approach in Germany [27]. As an energy management solution, an energy hub framework along with DSM methods was proposed for buildings in Serbia [28]. To identify electricity usage patterns in residences, a system to save electricity is proposed in Taiwan [29]. In Austria, autonomous optimal control of a domestic hot water heater was tested towards DSM opportunities [30], [31]; similarly, a smart control of domestic hot water cylinders with respect to future DSM opportunities was investigated in New Zealand [32].

Several studies in the literature have also considered DSM schemes that involve heating, ventilation, and air conditioning (HVAC) systems, as it is one of the dominating electricity consuming systems in buildings [33-35]. Although HVAC systems are associated with occupants' comfort [36], different DSM strategies are proposed which do not breach thermal comfort of the occupants. In addition, impacts on comfort also depend on thermal characteristics of the buildings [37]. Verrilli et al. (2016) proposed an algorithm that is able to perform peak load shaving, which takes into account the time variability of renewable generations, and thermal comfort in the building in a microgrid system [35]. Without compromising in-house thermal comfort, critical day pricing as a demand response scheme was also found effective [37]. 'Time of use price' and 'real-time price' were also found useful as DSM strategies for the HVAC system without any occupant discomfort; these schemes were also found valuable in reducing peaks by 5-20\% [38]. Ma et al. (2016) proposed a trade-off between demand response and discomfort in a smart grid scenario through power scheduling at residences [39]. In
Austin, USA, a controller was proposed for HVAC system, which is able to curtail peak load and maintains reasonable thermal comfort [40].

Furthermore, "potential and economics of electrical space heating in Swedish single-family dwellings" was investigated in Sweden [41]; direct load control in air conditioners as a DSM strategy and thermal comfort of the occupants were checked in Australia [42]. In Canada, a rulebased technique was used in programmable communicating thermostats (e.g. in air conditioners) to improve the user friendliness of the appliances while saving energy and cost [43]. In a similar fashion, to improve the DSM opportunities for thermostatically controlled load, a timer was proposed in a study in the USA [44]. A study in Belgium investigated the potential of active use of structural thermal mass in relation to DSM in buildings [45]. In addition to residential DSM options, studies were also conducted to identify the potentiality of DSM in commercial sectors such as shopping malls in Hong Kong [46, 47]. Different industrial sectors were also considered for DSM [48-50]. For instance, economic potential of intra-day DSM in a pulp and paper industry was conducted in Finland [48]. However, commercial and industrial DSM schemes are out of scope of this current study. In particular, residential DSM strategies are mainly considered in this article.

In terms of DSM in the developing world, far too little attention has been paid. To date, few studies have considered DSM opportunities in developing countries in a limited scale [51-53]. For instance, "demand response in Indian electricity market" was investigated [54]; technical and economic potential of DSM was assessed in Nigeria [55]; similarly, techno-economic and environmental benefits of DSM were also evaluated in Nigeria [53]; "Demand-side management in Nepal" was explored in [56]; energy conservation through human behaviour change at residences in Bangladesh was conducted in [15]. A recent study in China has identified the opportunities for and barriers to demand response [57].

Apart from these studies, in Brazil, it was found that resource management in relation to electricity consumption can save a large amount of energy; it showed that potable water saving of $10153835 \mathrm{~m}^{3} /$ year results in electricity savings of $4.4 \mathrm{GWh} /$ year [58].

\section{The case of Bangladesh}

Energy, in particular, electrical energy, is one of the predominant factors in the economic development for any country. Globally, the growth in overall energy demand was dominated by Asia and overall demand increased by $2.1 \%$ in 2017; consequently, energy-related $\mathrm{CO}_{2}$ emissions increased 


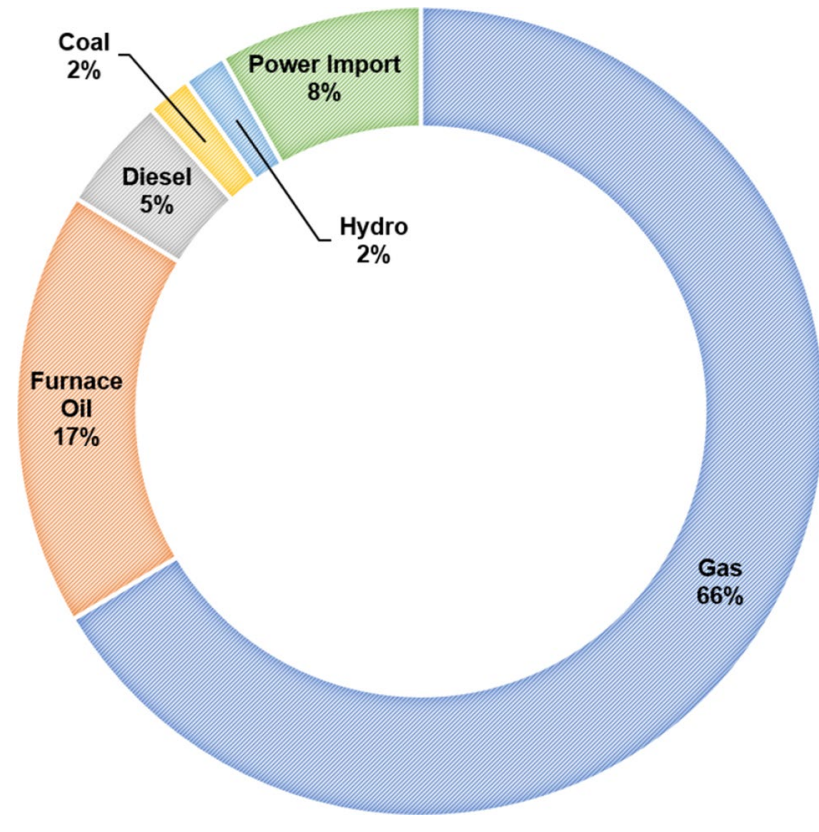

Fig. 1 Fuel-specific electricity generation shares for the fiscal year 2016-2017 in Bangladesh [60]

in the same year, which is the result of extensive use of fossil fuels in the electricity generation sector [1].

Bangladesh is not an exception to this trend; in 2015, 58.29 TWh of electricity was produced from fossil fuels; in contrast, only 0.57 and $0.16 \mathrm{TWh}$ were generated from hydro and solar/wind, respectively [59]. Net electricity generation for the fiscal year 2016-17 was approximately $57276 \mathrm{GWh}$. Fuel-specific generation shares are depicted in Fig. 1.

Bangladesh has been chosen as a case study as it has moved from a developing country to a lower middle income country category very recently, and so the government of Bangladesh is developing an energy-related policy for future development, which includes power generation sector [61]. Many developing nations are also moving in the same direction as Bangladesh at the moment and, thus, learnings from
Bangladesh could be helpful for these to formulate their energy policies well in advance.

Although electricity is indispensable for economic growth, extensive use of fossil fuels to generate electricity has adverse impacts on the environment, mainly in the form of greenhouse gas emissions. Hence, different measures have already been implemented around the globe to reduce emissions from the electricity sector, such as the introduction of DSM and renewable integration into the national grid. However, renewable integration into the electricity generation system of Bangladesh is limited due to resource constraints such as limited wind speed and limited hydro availability and storage capacity. Policy makers have, therefore, considered DSM strategies to reduce demand and emissions from the electricity sector. As a consequence, in 2015, with the support from the Japan International Cooperation Agency (JICA), the Sustainable and Renewable Energy Development Authority (SREDA) of Bangladesh developed an energy efficiency and conservation master plan (EECMP) up to 2030 as part of the DSM programme [62]. According to this plan, estimated demand reductions potential in different sectors are illustrated in Fig. 2. Clearly, the residential sector is able to contribute the most towards electricity demand reduction and this is possible if all household electrical appliances are replaced by highly efficient ones. Although it may be true that efficiency improvement of home appliances is an effective DSM option, there are some challenges and barriers associated with DSM deployment [63, 64]. Of these challenges, capital cost and implementation time dominate [65]. However, there are some other DSM opportunities that do not need to deal with these challenges. Residential energy-saving behaviour is one which has not been considered explicitly in the EECMP of Bangladesh.

Furthermore, "Results indicate that improving the energy efficiency of appliances in households leads to a significant reduction in electrical energy requirements but does not appear to have a significant affect on the peak electrical demand" [66]. It was found that efficiency improvement of electrical home appliances could reduce consumption on
Fig. 2 Sector-specific demand reduction potentials in Bangladesh (EE\&C: Energy Efficiency and Conservation). Source: EECMP 2015

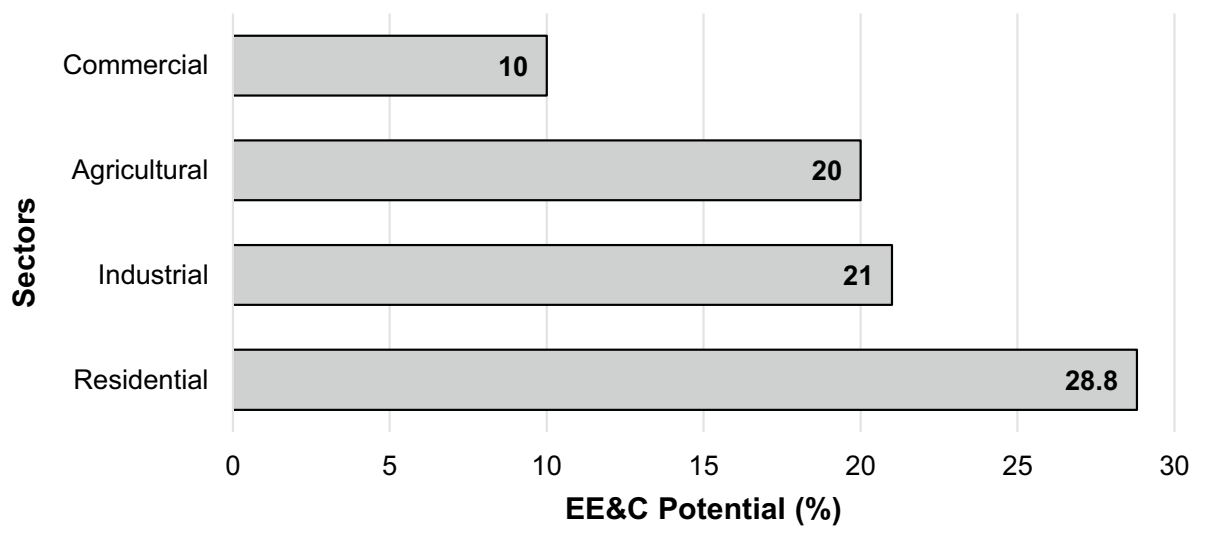


Fig. 3 Demand-side management program development key steps

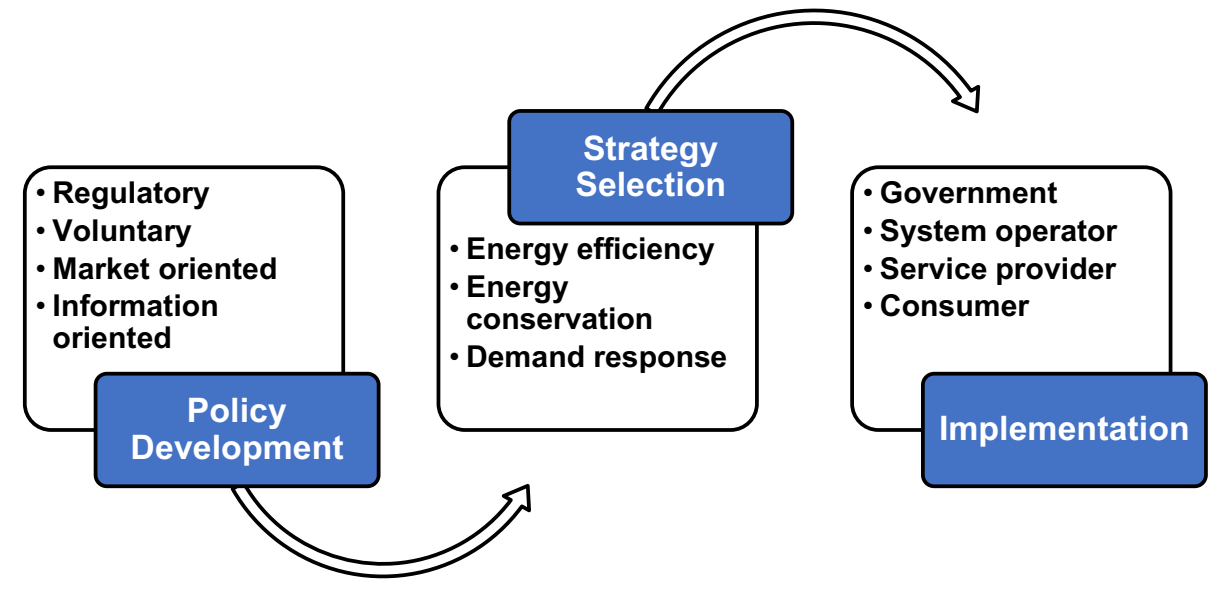

average by $23 \%$ per annum per household, which might not have any impact on peak demands.

Therefore, this study will investigate the potentiality of energy-saving behaviour as a DSM strategy in the developing world, focusing particularly on Bangladesh. The article is organized as follows: 'DSM program development steps' section explains the steps involved in developing a DSM policy. 'Types of demand response and its potentiality' section describes the different types of demand response schemes and their potentiality. 'Energy-saving behaviour adaptation' section presents the steps showing how new energysaving behaviour can be adapted. 'Energy-saving behaviour and its effectiveness towards DSM' section discusses the findings, and the final section concludes the study with possible policy implications.

\section{DSM program development steps}

The Electric Power Research Institute (EPRI) introduced the term 'Demand-Side Management' for the first time in 1980s. According to EPRI, DSM is defined as: " a series of measures intended to encourage specific groups of customers to modify their energy usage patterns in a manner consistent with the utility's DSM objectives while maintaining or enhancing customer satisfaction" [67]. In general, DSM is a measure to reduce load on the demand side (consumers) to ensure reliability on the supply side (electricity generation) and achieve benefits for both groups. For instance, it assures system efficiency, cost reduction for the grid operators; reduces electricity costs for end users, and also reduces carbon emissions from the electricity grid [68]. Nevertheless, the success of DSM depends on three key steps during the development process namely, DSM policy development, appropriate strategy selection, and implementation, as shown in Fig. 3.

DSM-related policy development can be conducted through one of the four ways as shown in Fig. 3 at step one. Of these, regulatory policy refers to the use of government laws, regulations and other instruments in achieving a desired goal (i.e. DSM success). From a voluntary point of view, a policy could be developed but participation in that program would be voluntary at the personal or organizational level. For example, a household might adopt a proposed DSM policy and practice it at their own pace without imposing any rules and regulations. Market-oriented policy development refers to a policy that is made by considering consumers' choice, that is, more consumer service-driven decision making. Information-oriented policy development involves policymaking based on available related information on a particular matter (e.g. DSM schemes).

The second step, strategy selection, deals with different available strategies in relation to DSM. These strategies might consider the energy efficiency improvement of different electrical home appliances for the residential DSM option or through energy conservation. In general terms, "energy conservation is the effort made to reduce the consumption of energy by using less of an energy service. This can be achieved either by using energy more efficiently (using less energy for a constant service) or by reducing the amount of service used ${ }^{1}$ ". On the other hand, demand response involves time-based, incentive-based, and energy-saving behaviours, explained further in Sect. 'Types of demand response and its potentiality'.

Implementation, the last step in Fig. 3, is completed by any one of the four entities mentioned, depending on the first step. For example, if the policy is developed as regulatory through available information, it would be implemented by the government. If the policy is market oriented, it could be implemented either by a system operator (the central electricity authority) or service providers (electricity distribution companies). On the other hand, if it is a voluntary policy it is most likely to be implemented by the end users (e.g. residential consumers).

\footnotetext{
$\overline{1}$ https://en.wikipedia.org/wiki/Energy_conservation
} 


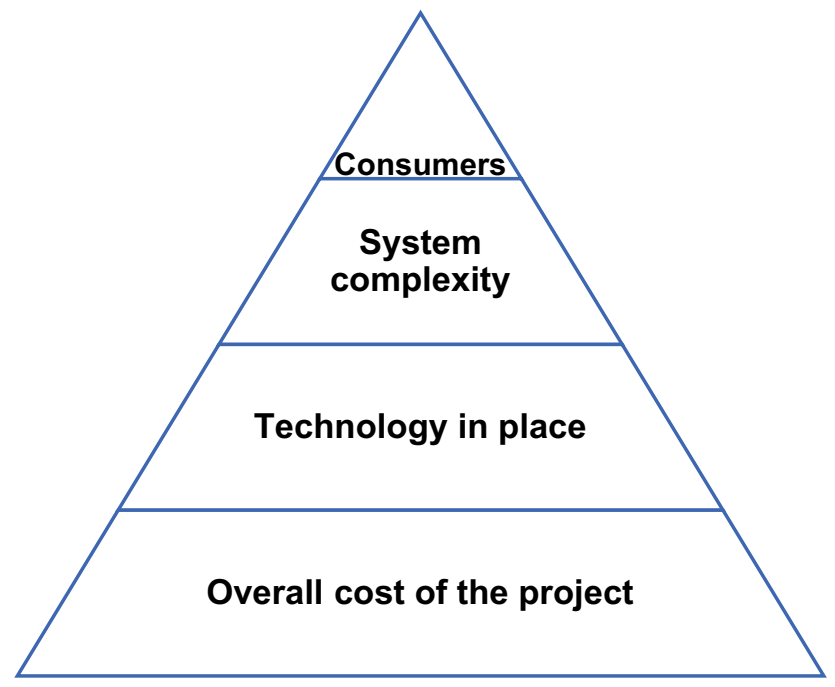

Fig. 4 Challenges in selecting appropriate DSM strategies

One of the challenging tasks in achieving successful DSM is the selection of appropriate DSM strategies (the second step in Fig. 3), which is the main focus of this study in the case of developing countries. The key challenges associated with this step are illustrated in Fig. 4.

In adopting any DSM strategy, the first challenge that needs to be dealt with is the overall cost involved for that strategy, such as capital costs. The next challenge is technology availability and compatibility for the selected DSM strategy, which may involve smart grids and meters, for example. Further issues include system complexity, how such complexity will be handled for the selected DSM strategy, for instance, generation fuel mix optimization in a highly renewable electricity system at the supply side [5]. The final challenge would be the consumers: how consumers response to adopt DSM strategy. Often, 'energy efficiency and conservation' as a DSM strategy does not require direct consumer involvement; in contrast, most demand response requires consumers' active participation in achieving a successful DSM program.

\section{Types of demand response and its potentiality}

Generally, demand response can be divided into two categories: time-based programs and incentive-based programs [69]. Time-based programs are designed to involve consumers in controlling electricity consumption during peak hours and gain benefit from it, whereas incentive-based programs are dealt with by electricity companies and provide incentives to consumers. Some common time-based programs are Time of Use (TOU) tariff, Real Time Pricing
(RTP), Critical Peak Pricing (CPP), and Peak Time Rebate (PTR). On the other hand, common incentive-based DSM programs are Direct Load Control (DLC), Interruptible or Curtailable rates (I/C), Demand Bidding (DB)/Buy Back (BB), Emergency Demand Response Program (EDRP), Capacity Market Program (CMP), and Ancillary Service Market (ASM). Details of these DSM strategies are well explained in [70-74]. However, to apply most of these DSM programs or strategies, electricity networks need to be on a smart grid. "A smart grid is an electricity system that uses modern information and communication technology (ICT) for better managing grid operation and balancing demand and supply" [75].

DSM strategies can be further categorized as 'stationary' and 'non-stationary' or 'dynamic'. In a stationary DSM scheme, "all consumers adopt fixed power consumption patterns as long as the system parameters (e.g. the consumers' desired power consumption patterns) do not change" [76]. Most of the DSM strategies nowadays such as TOU tariff are stationary. On the other hand, in 'nonstationary' scheme "the consumers may adopt different power consumption patterns (e.g. a consumer may shift its peak-time consumption today but not tomorrow) even if the system parameters remain the same" [76].

Numerous studies have explained 'non-stationary' or 'dynamic' demand response using different algorithms [12, 36, 77-80]. Most of these studies are simulation based. To date, only a few studies have tested the proposed algorithm in physical systems [36]. One of the most promising algorithms is reinforcement learning (RL), which is an agent-based artificial intelligent algorithm [81]. Study suggests that RL is not only able to design effective dynamic demand response schemes but also considers occupants' comfort at houses $[12,36]$. In addition, Lu et al. (2018) found that RL-based DSM scheme is able to maintain balance between supply and demand in the electricity market [12]. At the same time, it also reduces energy costs at the consumer end. Globally, electricity generation system is transitioning from fossil fuels to more renewable options to ensure a low-carbon future. Therefore, future demand response strategies should consider the intermittent nature of the renewable sources [82]. In this context, RL-based or dynamic DSM might be most appropriate [36, 79]. However, this requires further studies to confirm.

A number of studies also considered DSM in relation to renewable generations [26, 83-86]. For example, a study in Portugal found that adoption of DSM strategies could lead to delay in the penetration of renewable generation in the electricity sector [83]. Tascikaraoglu et al. (2014) investigated a smart home system in conjunction with renewable sources and found that "good compromise between the renewable energy production and household energy 


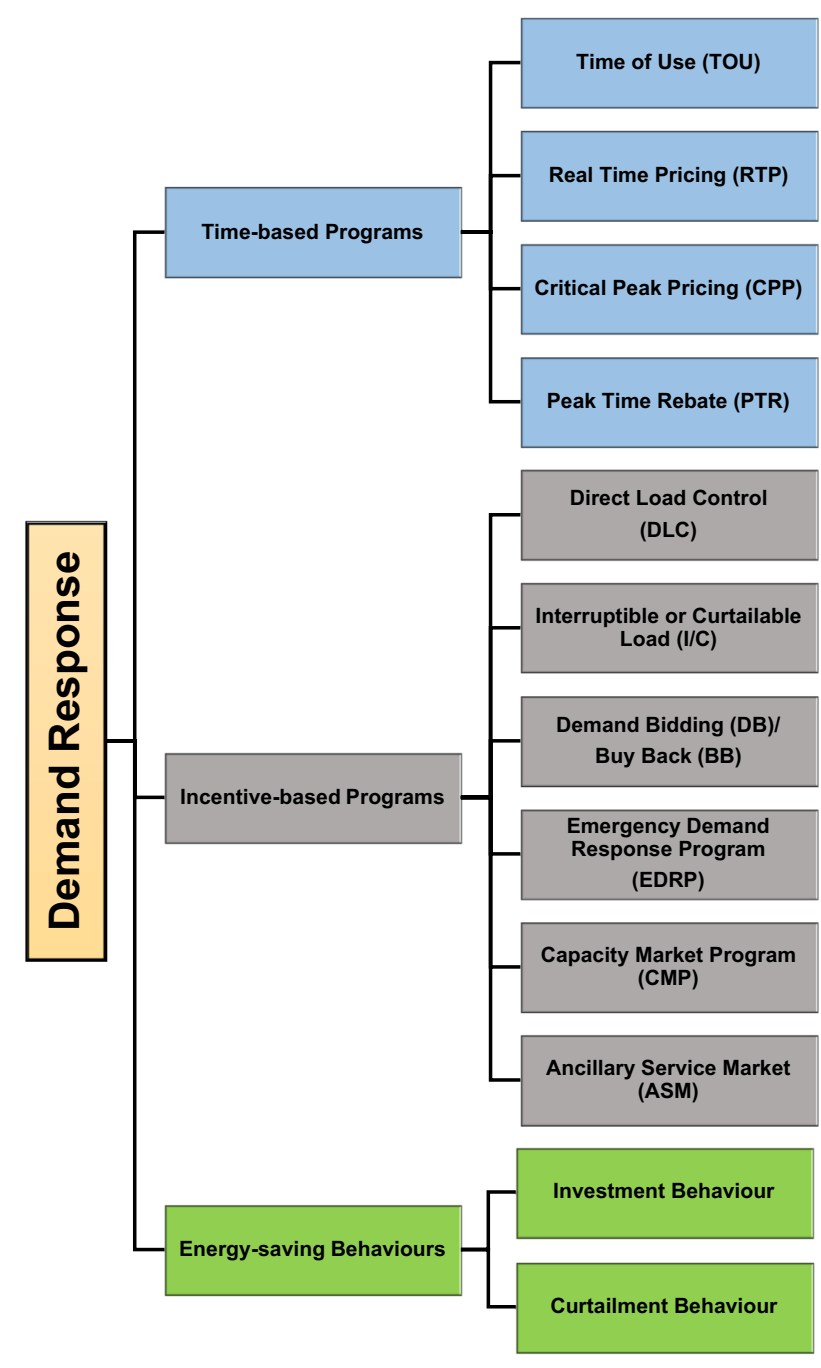

Fig. 5 Types of demand response strategies

consumption" can be achieved through demand flexibility [84]. A recent study considered residential demand-side management options by integrating electric vehicles and renewable energy sources in Croatia [86].

Energy-saving behaviour, on the other hand, is a potential demand response strategy that could play a vital role in managing electricity demand but has received less attention, as it is difficult to quantify its benefits compared with other demand response programs (e.g. TOU). Energy-saving behaviour can be categorized as investment and curtailment behaviour. The former approach requires financial investment to improve energy-saving behaviour, while the latter requires minimum or no monetary investment towards energy-saving [87-89]. All these demand response approaches are illustrated in Fig. 5.

Numerous studies in the literature have considered DSM strategies through time and incentive-based programs. For example, suitability of TOU tariff to reduce peak demand has been investigated in several studies [71, 90-93]; TOU can contribute to peak demand reduction by $1-6 \%[71,90$, 93]. Despite the fact that TOU can contribute to peak load reduction, it has been found to be an ineffective approach in reducing peak demand during peak hours for a family with children during weekdays in Australia [90]. The study of Spees and Lave (2008) has reported that real-time pricing (RTP) is more effective (10.4-17.7\% peak reduction) than TOU tariffs regarding peak demand reduction. Hence, TOU tariff is effective for flexible practices in the home which involve less social involvement (e.g. laundry and dishwashing). This finding is in line with the study of Laicane et al. (2015) in Latvia, who found that $24 \%$ and $13.5 \%$ peak load reduction can be achieved by shifting time of use of washing machines and dishwashers, respectively. Although CPP is expensive, this method of peak reduction was found useful for North America [71]. Detail reviews of these time and incentive-based demand response programs can be found in several recent studies, such as $[24,25,68,94,95]$.

An extensive literature review on energy-saving potential through human behaviour change was conducted in the UK [96] and found that energy-use behaviour change through different interventions could reduce electricity consumption up to $20 \%$. These interventions include, for example, direct feedback (e.g. smart meters) and indirect feedback (e.g. enhanced billing) [97]. A recent study in China found that electricity consumption was statistically lower for consumers who received consumption information (i.e. indirect feedback) from the meter readers than other houses [98]. This is in line with [99], who considered 42 feedback studies published between 1976 and 2010 and took into account feedback and pro-environmental behaviour in relation to household energy consumption; it was found that feedback is a promising strategy to conserve energy at houses. However, research also found that smart technologies such as in-home displays "....offer promise for encouraging energy conservation, but careful consideration should be given to the way that the feedback is framed' [100].

In an early study, it was found that goal setting along with feedback resulted in higher residential energy savings than goal setting only [101]. This finding was in line with [102], who found that goal setting could reduce energy consumption by between 19.5 and $21.9 \%$. Residential electricity consumption can be reduced by adapting simple behavioural change; for instance, a Finnish study found that based on monthly feedback and focused energy-saving advice, 54\% out of a total of 105 houses reduced energy consumption by turning off lights in unused rooms [103]. Importantly, it was also found that without use of smart technologies, receipt of weekly electricity bills could reduce electricity consumption from 0.6 to $1 \%$ in the USA [104]. In a similar manner, a study in Japan found that combination of monetary reward 


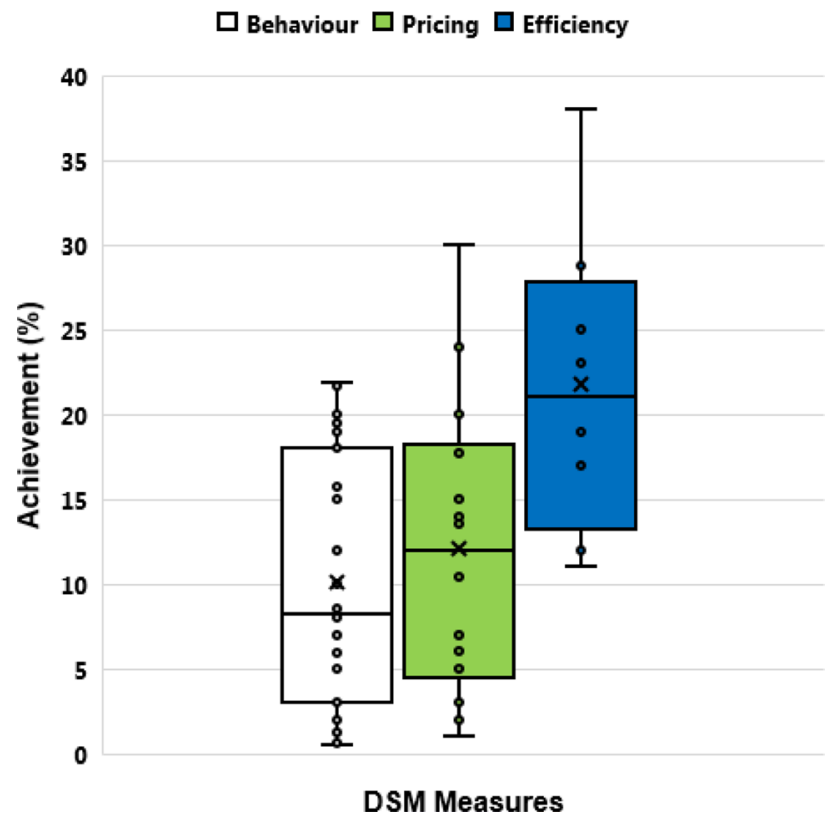

Fig. 6 Box and whisker plot showing percentages of achievement of DSM measures through different strategies found in the literature. Within each box, the horizontal line is the median value (cross represent average value) for that DSM, and the lower (and upper) edges of the box are the 25th (75th) percentile. Whiskers represent the upper and lower ranges and the dots outside the box represent outliers. Behaviour: consumers' energy-use behaviours; Efficiency: energy efficiency programs; Pricing: time or incentive-based programs. (Major references used: [37, 66, 96, 109, 111, 112])

with feedback could reduce more consumption (8.2\%) than monetary reward alone (5.9\%) [105].

In contrast with these studies, a study found that community-based programs such as 'EcoTeams' reduced electricity consumption by about 7\% in the UK and the Netherlands [106]. In a similar fashion, it was found that comparing electricity consumption of a household with its neighbours (i.e. peer comparisons) could reduce energy consumption by $2 \%$ in the USA [107]. Most importantly, the study outlined that: “...non-price interventions can substantially and cost effectively change consumer behavior..." [107]. A similar finding was also confirmed by [108], who found the reduction potential to be about $1.2 \%$. In contrast, individualized energy audit and consultation were found more effective than peer comparison; reduced electricity consumption was found to be 7.4\% [109]. Overall, "social influence approaches are generally effective at encouraging resource conservation, compared to a control or a comparison group" [110].

Furthermore, studies suggest that residential energy savings through behaviour change are faster than any other interventions [104, 113, 114]. In addition, peak time energy conservation through behaviour change can save between 15.7 and 21.7\% [113]. At the same time, Powells et al. (2014) have found some of the social practices that contribute to peak demand can be shifted through adaptable interventions (e.g. central laundry facility, where hot water is provided and heated by a solar heating system). The authors have also identified some practices such as cooking and meal times which are not flexible at all for families on shift work. In reviewing the literature, the success of different DSM strategies that can be achieved is depicted in Fig. 6 . It can be seen that energy-saving behaviour as a demand response strategy could reduce demand by between 0.5 and $21.9 \%$, with an average of $10.05 \%$ (median $8.2 \%$ ). On the other hand, efficiency improvement and time or incentivebased (pricing) strategies are able to reduce demand within the range of 1 to $30 \%$ and 11 to $38 \%$, respectively.

\section{Factors responsible for residential demand}

Effective demand-side management strategy design for the residential sector depends on proper identification of factors that are responsible for driving electricity demand at houses. A large and growing body of literature has investigated different household factors such as building characteristics, socio-demographic characteristics and found relationship in driving residential electricity demand [115-121]. For example, Brounen et al. (2012) found that electricity consumption at houses varies predominantly due to family composition and income of the household [117]. Dwelling characteristics, in particular, size of the house, have significant impact on electricity consumption and related expenditure [118]. In India, Filippini and Pachauri (2004) found that area of the house and demographic characteristics such as 'age of the head of the house' have large impact on electricity consumption in urban area [119]. A recent review study considered most of these household factors that contribute to electricity demand including peak demand at houses, in which the author categorized the factors as 'climate and location of the dwelling', 'physical characteristics of the dwelling', 'household activities and services', 'economic capability', 'sociodemographic characteristics', 'cost of energy', and 'potential drivers of future residential consumption' [115].

Demand reduction, particularly during network peak hours, is crucial in ensuring security of supply and network reliability. Previous study suggests that demand response could reduce peak demand by $43 \%$ in the residential sector, whereas it is only $13 \%$ for both commercial and industrial sectors together in the USA [14]. Thus, demand reduction through DSM strategies by considering different household factors is indispensable, so that a good balance between supply and demand is maintained. A recent simulation study in South Africa showed that household participation in DSM through optimal dispatch of household appliances such as cloth washers and cloth dryers could save a considerable amount of electricity, which in turns ensures security of 
Fig. 7 Different DSM strategies' implementation time and associated investment cost (illustrative example)

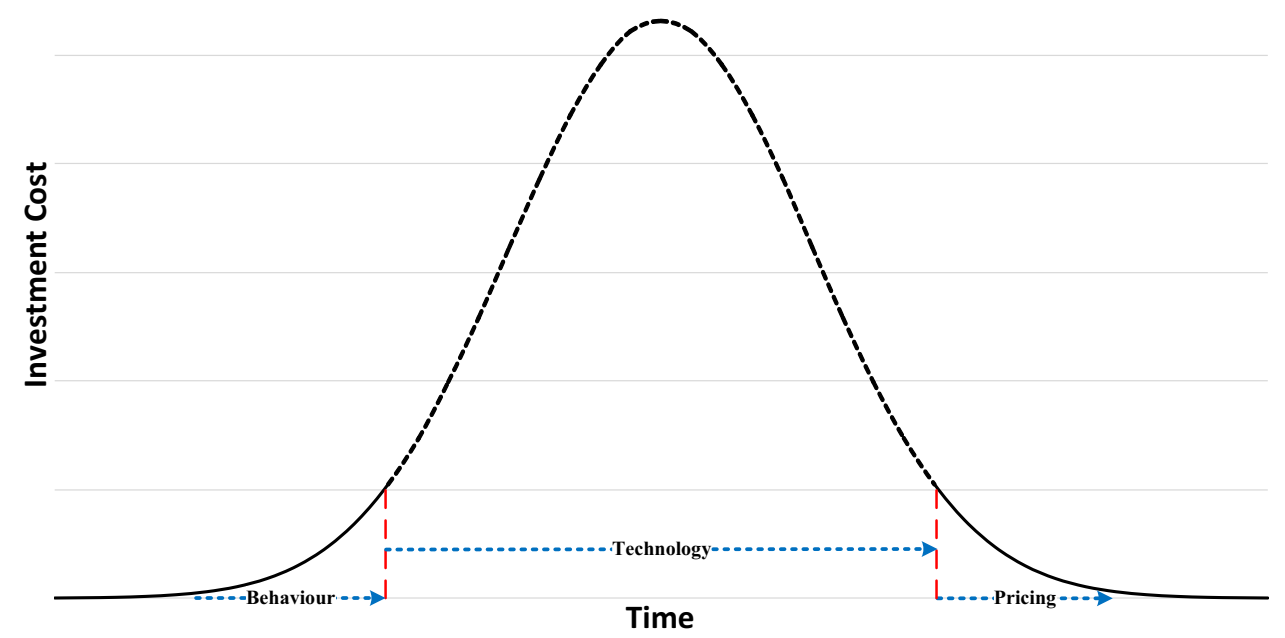

supply during peak hours [122]. Another study in South Africa proposed a 'combined energy management system' that considers both supply and demand sides for proper resource management [123]. Li and Pye (2018) in the UK found that DSM flexibility involving household smart appliances and electric vehicles increases electricity system flexibility [124].

In summary, DSM strategies including household factors that contribute most to residential electricity demand are crucial in ensuring electricity network's reliability, security of supply and maintaining a good balance between supply and demand for the electricity system of any country.

\section{DSM strategies in Bangladesh}

Long-term DSM programs in Bangladesh [62] did not include any strategies in relation to energy-saving behaviour change at residences extensively, except limited awareness development programs through electronic and print media [60]. It is evident from the literature that different DSM strategies must deal with some investment costs at different levels of implementation, which has been depicted in Fig. 7. This is an illustrative example, as the investment cost (magnitude along the $\mathrm{x}$-axis) and associated time (along the y-axis) to implement the DSM depend on many other factors in the developing world, such as government policy support and long-run self-sustainability of financial support to the program [125]. Nonetheless, the relation between investment cost and implementation time will follow the trend as indicated in Fig. 7.

Evidently, technology involvement (e.g. efficient home appliance deployment, smart grid) in achieving DSM costs more than any other strategies, added to which is the lengthy time period required (cf. Fig. 7). On the other hand, energy-use behaviour change as a demand response strategy on the domestic level includes minimum or no cost, which requires relatively short periods of time to achieve demand reduction. Similarly, different pricing schemes (e.g. TOU) in relation to DSM after technology deployment would also take short periods for implementation.

EECMP-2015 did not consider this initial step of DSM in domestic settings (i.e. behaviour change towards energy conservation), but rather focused directly on the second step (see Fig. 7) efficient technology deployment, which requires a considerable amount of investment and longer time periods to be implemented [62]. As a consequence, although the planned DSM strategy was proposed in 2015, its outcomes are still insignificant [60].

In achieving a properly planned DSM strategy for the residential sector for any nation, four consecutive steps need to be followed over time as illustrated in Fig. 8. Firstly, immediate demand response, which is achievable through consumer behaviour change, needs to be initiated and this would take about 12 to 15 months, with about $15 \%$ DSM achievement. Secondly, appropriate technology deployment such as energy-efficient appliances, smart grid and in-home displays would take longer, with about a further 40\% DSM achievement. Thirdly, after related technology deployment, appropriate pricing schemes (cf. Fig. 5) would ensure a further $30 \%$ DSM achievement within 10 to12 months. Finally, 15\% DSM achievement would be implemented through proper code and regulations, taking about a further 10 to 12 months.

Although it may be true that the potential for reducing household electricity demand will depend on users' proper interaction with the latest energy management technologies, such as in-home displays [11], these also have limitations such as limited efficacy [126], whereas studies 
Fig. 8 Different demand response strategies' implementation time and achievement percentages for DSM program planning (solid line: behaviour; square dotted line: technology; round dotted line: pricing; long dash line: regulation)
Fig. 9 Steps in adapting a new energy-saving behaviour at home [115]
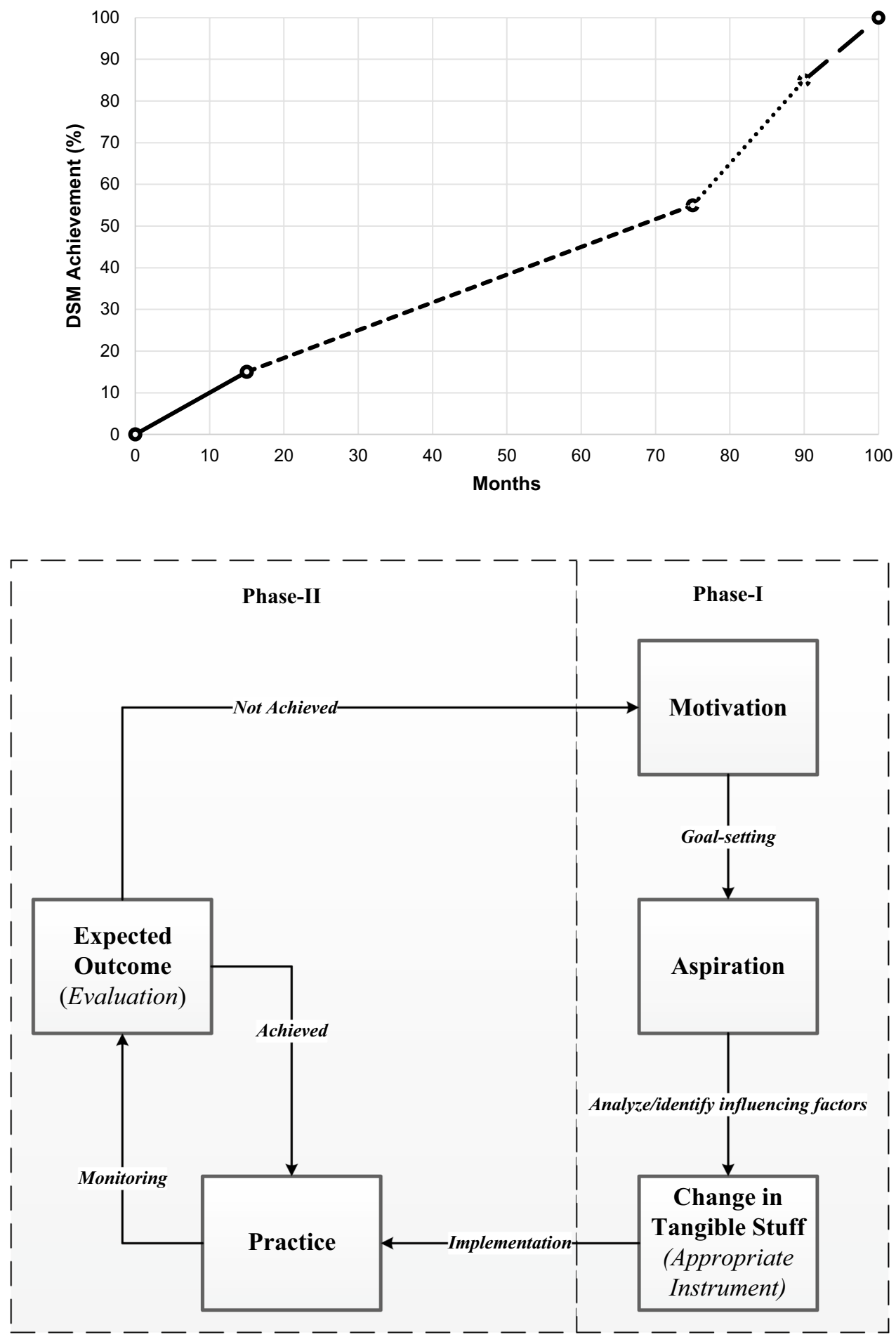

show that demand response programs, such as targeting energy-saving behaviours in homes, can be implemented faster than any other approaches such as technological efficiency improvement and are a relatively effective strategy that provides immediate results [104, 113, 114, 127, 128].

\section{Energy-saving behaviour adaptation}

Generally, energy conservation can be achieved in two ways: first, through technology deployment, such as energy-efficient appliances; second, human or consumers' energy-use behaviour change (i.e. energy-saving 
behaviour) in their homes. The former requires considerable time and costs to be implemented. In contrast, the latter can be achieved relatively faster than the former with no or minimum costs. New energy-saving behaviour in homes can be adapted, which follows a cyclic order as depicted in Fig. 9, which was first proposed in [115], involving two phases. Phase I deals with personal goal setting, analysing the influencing factors related to energy consumption and identifying appropriate technology or instruments to achieve the goal. In general, phase I considers human psychology towards a new behaviour adaptation. On the other hand, in phase II, the psychological thought in relation to new energy-use behaviour applies to the real world that is, practice and evaluation. This is explained with an example below.

To change any energy-use behaviour, it is necessary to be motivated towards this practice, as the first step towards new energy-associated behaviour in residences. This motivation can be achieved through different sources, for instance, from society, related campaigns, education or even from economic factors. For example, a person might be motivated to reduce their electricity bill by reducing unwanted consumption at home (lights remaining on in an unoccupied room). This motivation inspires the person to set a goal in relation to electricity reduction that is 'aspiration'. In achieving the targeted goal, the person makes affordable changes in concrete terms, for example, replacing conventional bulbs with compact fluorescent lamps. Next, the person tries to learn and practice possible energy-saving behaviours such as switching off electric loads (e.g. lights, fans) in unoccupied rooms: practice. Later, at the end of the month the consumer measures their level of achievement by checking their electricity bill or by any other means, for example, indirect feedback: expected outcome. If the desired outcome is achieved, this practice and outcome cycle continues, otherwise the process starts from the beginning (i.e. motivation step). Although studies suggest that this type of new behaviour change does not always persist $[129,130]$, it might be an effective energy conservation step at the beginning of any DSM program. For example, this type of energy conservation might be effective before technology upgrades, such as energy-efficient appliance deployment, with immediate results in energy conservation, which is about $21.7 \%$ (maximum) [113] and faster compared with other energy conservation strategies [104, 114].

\section{Energy-saving behaviour and its effectiveness towards DSM}

One study found that “... a changeover to more energy-efficient appliances will have a beneficial effect on the electrical energy consumption of domestic households, with annual average reductions in electrical consumption of $23 \%$ for the households under investigation, such a measure may not necessarily be effective in reducing daily peak power demands of the individual households" [66]. In contrast, energy conservation through occupants' energy-use behaviour change can save electricity up to $21.7 \%$ during peak demand hours [113]. At the same time, energy-use behaviour change does not require any significant capital cost. Thus, energy-saving behaviour could be an effective DSM options in any environment, in particular, developing countries, where DSM strategy deployment is either at the planning stage or at initial implementation stage.

The EECMP of Bangladesh has found that efficiency improvement of home appliances would reduce electricity demand in the residential sector by about $28.8 \%$ (Fig. 2), yet this requires a long implementation time, whereas inclusion of energy-saving behaviour as a demand response strategy in homes along with this EECMP might achieve a maximum demand reduction of about $50.7 \%$ with a minimum or no extra costs. For long-term DSM planning, it must include energy-use behaviour change at its initial stage to achieve immediate demand reduction. For instance, energy-saving behaviour could reduce the demand by an average of $10.05 \%$ (see Fig. 6). However, the level of achievement for Bangladesh might vary between $29.3 \%$ and $50.7 \%$ with energy-saving success of 0.5 and $21.9 \%$, respectively. Hence, to derive maximum outcome from this strategy, it is necessary to focus on some particular issues. To make the energy-saving behaviour an effective DSM program and deliver value, it needs to be customer friendly by ensuring the following key elements [131]:

(i) Communication, outreach and information sharing

(ii) Consumer enrolment

(iii) Consumers' experience

(iv) Measurement and validation

Communication, outreach and information sharing with consumers are the vital pillars towards a successful DSM that involves residential energy-saving behaviour. At the beginning of this demand response program, a campaign would be an effective approach to involve people by sharing-related benefits of the program and to inform them that their potential participation would help to achieve certain DSM goals, which would be beneficial for both the consumer and supplier as well as for the environment. Most often, involving local institutions and community leaders seem advantageous in achieving maximum involvement of the consumers.

Consumer enrolment is the second pillar to ensure effective energy-saving behaviour in a focused demand response program. It is important to define easy and effective ways or methods of enrolment for consumers to the program. It is necessary to target particular consumers, so 


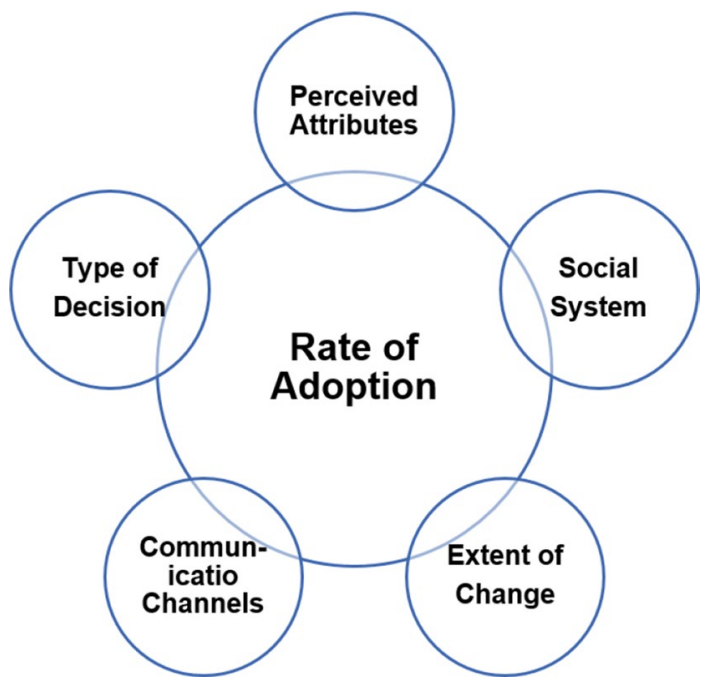

Fig. 10 Factors that impact the rate of adoption of any new innovations

that energy-saving scheme can achieve immediate success, which would be a reference for other consumers to be motivated and effectively engage in the program. In selecting the consumers for enrolment, the young generation is a good choice as they are more responsive to any new positive technological changes. However, the rate of adoption depends on many other factors, illustrated in Fig. 10 and detailed in [132].

Perceived attributes of any innovation depend on several variables such as relative advantage of the program or innovation, compatibility, complexity, trialability, and observability. Types of decision may be optional, collective or authoritative. Effectiveness of communication channels in adopting the program varies from mass media to interpersonal. The nature of the social system also contributes to the adoption of the program based on its norms and degree of interconnectedness. Extent of change refers to 'the relationship between rate of adoption and change agents' efforts' and it was found that ".... the greatest response to change agent effort occurs when opinion leaders are adopting" [132] .

Consumer experience is the next pillar that needs particular attention. Essentially, a consumer's expectation from the energy-saving program needs to be assessed at regular intervals - weekly, fortnightly or monthly. Importantly, the level of success achieved by consumers needs to be clearly demonstrated to them, which would inspire further active participation. In contrast, if the achievement is not satisfactory, further suggestions such as development of technical knowledge through training or in-home tutorials and possible required changes in the home need to be recommended by the staff employed for the project. In doing so, it is also important to ensure proper communication channels between consumers and the staff of the program, so that immediate support via phone or internet can be provided to the consumers depending on their needs.

Measurement and validation of the program are crucial for overall success of any project. Periodic measurement of overall project achievement needs to be assessed with respect to the predefined goals. If necessary, these goals could be reassigned in accordance with the project requirements and its continuous success. If the program is to be a successful one, it is essential to [131]:

- Track the improvement with respect to the reference or base case scenario.

- Monitor the overall growth of the program, including all aspects, such as marketing, acquisition, achievement, retention and benefits.

- Ensure reporting for different segments of the program such as executive, financial, operations.

- Redefine the goals and associated targets, based on the learnings from the program.

- Share the achievement and success with employees and consumers through different means (e.g. electronic or print media) to motivate them further.

Despite the benefits of energy-saving behaviour as a demand response strategy as mentioned earlier, it has some limitations too [87] such as: achievements are temporary and need continuous motivation [129, 130, 133]. In addition, there might be direct and indirect 'rebound effects' due to this energy saving, that is, savings from energy services might be used for other similar services [134-138]. The concept of 'rebound effect' refers to a set of mechanisms that would be able to reduce the cost of the energy service; however, this reduction might increase the household energy consumption totally or partially negating the reduction achieved by the mechanisms [139]. In direct rebound effect, the consumers might be motivated to consume more electricity at off-peak period. On the other hand, in indirect rebound effect, the consumers may purchase other goods and services which might have similar negative impacts. Nevertheless, 'indirect rebound is bounded by the consumer budget constraint' [139]. For instance, a study in Beijing, China found that increase in energy efficiency of certain electrical home appliances such as air conditioners, cloth washers, and microwave ovens increases the indirect rebound effect significantly along with direct rebound [140].

Although it may be true that residential energy-saving has these shortcomings, it is one worthwhile strategy to adopt 
at the beginning of any DSM plan as it requires a minimum amount of capital cost with immediate success.

\section{Conclusion and policy implications}

Most of the demand-side management studies to date have tended to focus on developed nations, and developing countries have received less attention in this particular aspect. Possible reasons might be technological limitations (e.g. smart grid) associated with capital costs in relation to the DSM strategy development and deployment. Although it may be true that there exist technological limitations in the developing world, there are other potential DSM options available that might reduce electricity demand including peak demand, particularly at the household level. Energy-use behaviour change of householders is one of these potential DSM strategies, which not only requires minimum time to be implemented but also provides immediate success as a demand response program. Most often, this potential option has been neglected or underestimated in the developing world in relation to national DSM strategy development.

Bangladesh developed its national DSM plan in the electricity sector considering energy efficiency and conservation measures in 2015. This is a beneficial and timely initiative, but the plan did not extensively consider all the DSM potential strategies. For instance, energy-saving behaviour has not been considered in the plan at all, whereas studies suggest that energy-saving through householders' behaviour change could potentially contribute energy reduction in the range of $0.5-21.9 \%$. In the light of the findings presented in this study, a national DSM plan for Bangladesh may need to consider energy-saving behaviour as a strategy to obtain full benefit of the DSM at each step of the program.

Importantly, it is essential to consider each of the possible DSM strategies when planning for a national DSM program, particularly for developing nations where DSM is not yet deployed or at its initial stage. Although this study has considered the national DSM plan of Bangladesh as a case study, the findings from this study can be a useful lesson for other developing nations, who are in the process of developing their own national DSM programs. Towards any policymaking in relation to DSM strategy development, it is essential to note the following:

- As capital cost of any project is a major barrier (i.e. economic barrier) in most of the developing countries [65], energy-use behaviour change could be a potential demand response scheme at the beginning of a long-term DSM plan.

- Public education or related knowledge development through campaigns in relation to any new demand response strategy deployment is an important aspect towards the overall success of the DSM program.

- Ensuring more informative electricity bills for consumers $[107,114]$ would be a key element in motivating more people to participate in energy-use behaviour change towards an effective demand response program (an illustrative example is shown in Fig. 11 in the Appendix).

- A second DSM strategy could be appropriate technology deployment (energy efficiency measures or smart grid development). Thus, applying time and incentive-based DSM programs would be beneficial.

- Not all energy efficiency-based measures would be viable in achieving DSM; hence, modest pilot projects might be an effective option in identifying most appropriate options, which would be successful in the longer term. Moreover, subsidies can be an effective step at the beginning of any pilot project.

- Implementation of related regulations might be the final step in achieving maximum outcomes of DSM strategy deployment.

Open Access This article is distributed under the terms of the Creative Commons Attribution 4.0 International License (http://creativeco mmons.org/licenses/by/4.0/), which permits unrestricted use, distribution, and reproduction in any medium, provided you give appropriate credit to the original author(s) and the source, provide a link to the Creative Commons license, and indicate if changes were made.

\section{Appendix}

See Fig. 11. 
Fig. 11 An illustrative example of more informative electricity bill

This month you used electricity that was almost the same as your most efficient neighbor.

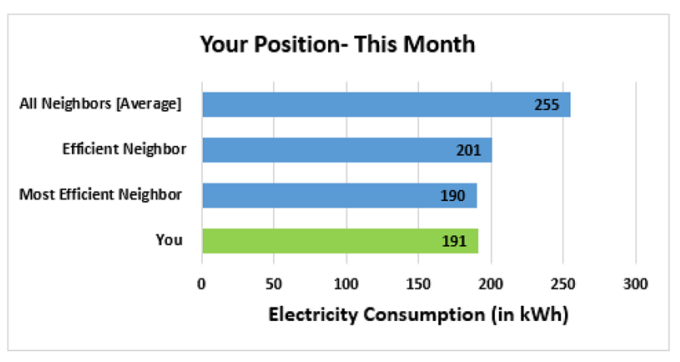

You saved $19 \mathrm{kWh}$ of electricity this month comparing with the previous month.

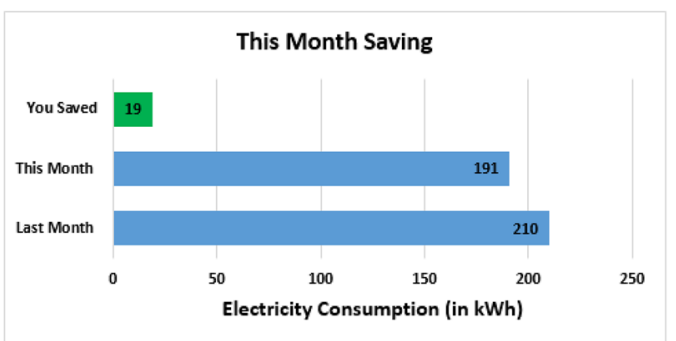

How much cost have you saved this month and previously, and your detailed bill can be found at the back of this page.

The summer is the best season for you to save more energy and cost.

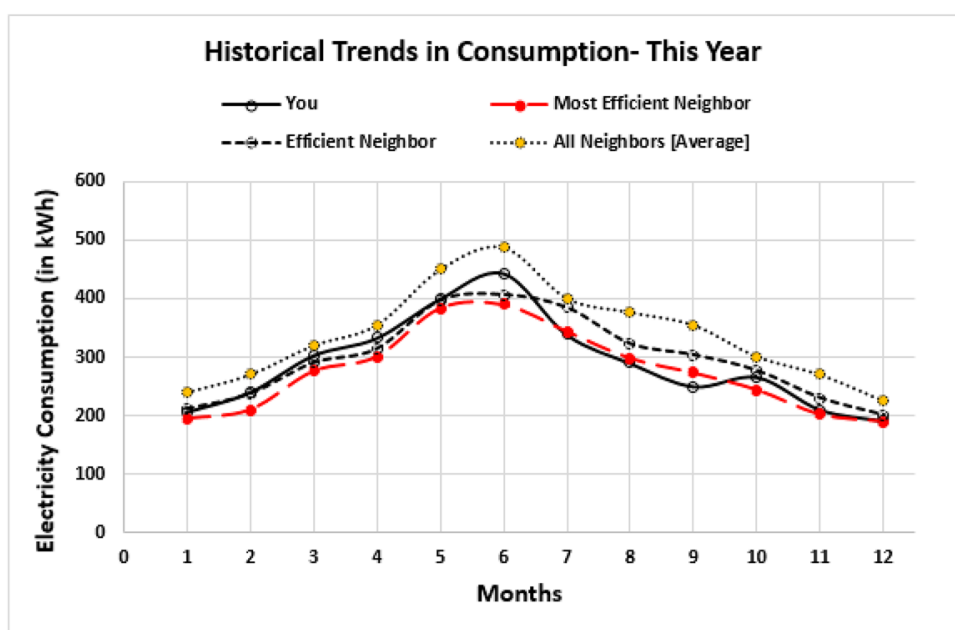

»> If you need suggestion how to save more please contact our Energy Conservation Customer Supoort Centre.

» How to contact: Please see the back of this page.

Your status this month:

Very Good 


\section{References}

1. IEA: Global Energy and CO2 Status Report 2017, 2018. https:// www.iea.org/publications/freepublications/publication/GECO2 017.pdf. Accessed 29 Sept 2018

2. Khan, I.: Importance of GHG emissions assessment in the electricity grid expansion towards a low-carbon future: a time-varying carbon intensity approach. J. Clean. Prod. 196, 1587-1599 (2018). https://doi.org/10.1016/j.jclepro.2018.06.162

3. Gustafsson, M.S., Myhren, J.A., Dotzauer, E.: Potential for district heating to lower peak electricity demand in a mediumsize municipality in Sweden. J. Clean. Prod. (2018). https://doi. org/10.1016/j.jclepro.2018.03.038

4. Saffari, M., de Gracia, A., Fernández, C., Belusko, M., Boer, D., Cabeza, L.F.: Optimized demand side management (DSM) of peak electricity demand by coupling low temperature thermal energy storage (TES) and solar PV. Appl. Energy 211, 604-616 (2018). https://doi.org/10.1016/j.apenergy.2017.11.063

5. Khan, I., Jack, M.W., Stephenson, J.: Analysis of greenhouse gas emissions in electricity systems using time-varying carbon intensity. J. Clean. Prod. 184, 1091-1101 (2018). https://doi. org/10.1016/j.jclepro.2018.02.309

6. Khan, I.: Temporal carbon intensity analysis: renewable versus fossil fuel dominated electricity systems. Energy Sources A Recover Util. Environ. Eff. 41, 309-323 (2019). https://doi. org/10.1080/15567036.2018.1516013

7. Jiang, Y.H., Levman, R., Golab, L., Nathwani, J.: Analyzing the impact of the 5CP Ontario peak reduction program on large consumers. Energy Policy. 93, 96-100 (2016). https://doi. org/10.1016/j.enpol.2016.02.052

8. Turner, W.J.N., Walker, I.S., Roux, J.: Peak load reductions: electric load shifting with mechanical pre-cooling of residential buildings with low thermal mass. Energy. 82, 1057-1067 (2015). https://doi.org/10.1016/j.energy.2015.02.011

9. Gellings, C.: The concept of demand-side management for electric utilities. Proc. IEEE 73, 1468-1470 (1985). https://doi. org/10.1109/PROC.1985.13318

10. Gellings, C., Barron, W., Betley, E., England, W., Preiss, L., Jones, D.: Integrating demand-side management into utility planning. IEEE Trans. Power Syst 1, 81-87 (1986). https://doi. org/10.1109/TPWRS.1986.4334958

11. Ford, R., Pritoni, M., Sanguinetti, A., Karlin, B.: Categories and functionality of smart home technology for energy management. Build. Environ. 123, 543-554 (2017). https://doi.org/10.1016/j. buildenv.2017.07.020

12. Lu, R., Hong, S.H., Zhang, X.: A dynamic pricing demand response algorithm for smart grid: reinforcement learning approach. Appl. Energy 220, 220-230 (2018). https://doi. org/10.1016/j.apenergy.2018.03.072

13. Bergaentzlé, C., Clastres, C., Khalfallay, H.: Demand-side management and European environmental and energy goals: an optimal complementary approach. Energy Policy. 67, 858-869 (2014)

14. Faruqui, A., Hledik, R., Newell, S., Pfeifenberger, H.: The power of 5 percent. Electr. J. 20, 68-77 (2007). https://doi. org/10.1016/j.tej.2007.08.003

15. Khan, I., Halder, P.K: Electrical energy conservation through human behavior change: perspective in Bangladesh. Int. J. Renew. Energy Res. 6, 43-52 (2016). http://www.ijrer.com/index .php/ijrer/article/view/3030. Accessed 30 Sept 2018

16. Strbac, G.: Demand side management: benefits and challenges. Energy Policy. 36, 4419-4426 (2008). https://doi.org/10.1016/j. enpol.2008.09.030

17. Nan, S., Zhou, M., Li, G.: Optimal residential community demand response scheduling in smart grid. Appl. Energy 210, 1280-1289 (2018). https://doi.org/10.1016/j.apenergy.2017.06.066
18. Eissa, M.M.: First time real time incentive demand response program in smart grid with "i-Energy" management system with different resources. Appl. Energy 212, 607-621 (2018). https:// doi.org/10.1016/j.apenergy.2017.12.043

19. Zafar, R., Mahmood, A., Razzaq, S., Ali, W., Naeem, U., Shehzad, K.: Prosumer based energy management and sharing in smart grid. Renew. Sustain. Energy Rev. 82, 1675-1684 (2018). https://doi.org/10.1016/j.rser.2017.07.018

20. van Leeuwen, R.P., de Wit, J.B., Smit, G.J.M.: Review of urban energy transition in the Netherlands and the role of smart energy management. Energy Convers. Manag. 150, 941-948 (2017). https://doi.org/10.1016/j.enconman.2017.05.081

21. Romero Rodríguez, L., Sánchez Ramos, J., Álvarez Domínguez, S., Eicker, U.: Contributions of heat pumps to demand response: a case study of a plus-energy dwelling. Appl. Energy. 214, 191204 (2018). https://doi.org/10.1016/j.apenergy.2018.01.086

22. Yin, C.J., Wu, H.W., Locment, F., Sechilariu, M.: Energy management of DC microgrid based on photovoltaic combined with diesel generator and supercapacitor. Energy Convers. Manag. 132, 14-27 (2017). https://doi.org/10.1016/j.encon man.2016.11.018

23. Bahl, B., Lampe, M., Voll, P., Bardow, A.: Optimization-based identification and quantification of demand-side management potential for distributed energy supply systems. Energy. 135, 889-899 (2017). https://doi.org/10.1016/j.energy.2017.06.083

24. Alasseri, R., Tripathi, A., Joji Rao, T., Sreekanth, K.J.: A review on implementation strategies for demand side management (DSM) in Kuwait through incentive-based demand response programs. Renew. Sustain. Energy Rev. 77, 617-635 (2017). https:// doi.org/10.1016/j.rser.2017.04.023

25. Celik, B., Roche, R., Suryanarayanan, S., Bouquain, D., Miraoui, A.: Electric energy management in residential areas through coordination of multiple smart homes. Renew. Sustain. Energy Rev. 80, 260-275 (2017)

26. Kakran, S., Chanana, S.: Operation management of a renewable microgrid supplying to a residential community under the effect of incentive-based demand response program. Int. J. Energy Environ. Eng. 10, 121-135 (2019). https://doi.org/10.1007/s4009 5-018-0286-4

27. Gils, H.C.: Economic potential for future demand response in germany-modelling approach and case study. Appl. Energy 162, 401-415 (2016)

28. Batić, M., Tomašević, N., Beccuti, G., Demiray, T., Vraneš, S.: Combined energy hub optimisation and demand side management for buildings. Energy Build. 127, 229-241 (2016). https:// doi.org/10.1016/j.enbuild.2016.05.087

29. Chou, C.C., Chiang, C.T., Wu, P.Y., Chu, C.P., Lin, C.Y.: Spatiotemporal analysis and visualization of power consumption data integrated with building information models for energy savings. Resour. Conserv. Recycl. 123, 219-229 (2017). https:// doi.org/10.1016/j.resconrec.2016.03.008

30. Kepplinger, P., Huber, G., Petrasch, J.: Field testing of demand side management via autonomous optimal control of a domestic hot water heater. Energy Build. 127, 730-735 (2016). https://doi. org/10.1016/j.enbuild.2016.06.021

31. Kepplinger, P., Huber, G., Petrasch, J.: Autonomous optimal control for demand side management with resistive domestic hot water heaters using linear optimization. Energy Build. 100, 50-55 (2015). https://doi.org/10.1016/j.enbuild.2014.12.016

32. Jack, M.W., Suomalainen, K., Dew, J.J.W., Eyers, D.: A minimal simulation of the electric demand of a domestic hot water cylinder. Appl. Energy 211, 104-112 (2018)

33. Yan, C., Xue, X., Wang, S.: A novel air-conditioning system for proactive power demand response to smart grid. Energy Proc. 61, 25-28 (2014). https://doi.org/10.1016/j.enconman.2014.09.072 
34. Elahee, M.K.: Energy management and air-conditioning in buildings in mauritius: towards achieving sustainability in a smallisland developing economy vulnerable to climate change. Energy Procedia. 62, 629-638 (2014). https://doi.org/10.1016/j.egypr o.2014.12.426

35. Verrilli, F., Gambino, G., Srinivasan, S., Palmie, G., Del Vecchio, C., Glielmo, L.: Demand side management for heating controls in microgrids. IFAC-Pap Online. 49, 611-616 (2016). https://doi. org/10.1016/j.ifacol.2016.03.123

36. Vázquez-Canteli, J.R., Nagy, Z.: Reinforcement learning for demand response: a review of algorithms and modeling techniques. Appl. Energy 235, 1072-1089 (2019). https://doi. org/10.1016/j.apenergy.2018.11.002

37. Darby, S.J., McKenna, E.: Social implications of residential demand response in cool temperate climates. Energy Policy. 49, 759-769 (2012). https://doi.org/10.1016/j.enpol.2012.07.026

38. PNNL, Pacific Northwest GridWise Testbed Demonstration Projects: Part I. Olympic Peninsula Project, Washington (2007). https://www.pnnl.gov/main/publications/external/technical_ reports/PNNL-17167.pdf. Accessed 29 Sept 2018

39. Ma, K., Yao, T., Yang, J., Guan, X.: Residential power scheduling for demand response in smart grid. Int. J. Electr. Power Energy Syst. 78, 320-325 (2016). https://doi.org/10.1016/j.ijepe s.2015.11.099

40. Yoon, J.H., Bladick, R., Novoselac, A.: Demand response for residential buildings based on dynamic price of electricity. Energy Build. 80, 531-541 (2014). https://doi.org/10.1016/j. enbuild.2014.05.002

41. Nyholm, E., Puranik, S., Mata, É., Odenberger, M., Johnsson, F.: Demand response potential of electrical space heating in Swedish single-family dwellings. Build. Environ. 96, 270-282 (2016). https://doi.org/10.1016/j.buildenv.2015.11.019

42. Zhang, F., de Dear, R., Candido, C.: Thermal comfort during temperature cycles induced by direct load control strategies of peak electricity demand management. Build. Environ. 103, 9-20 (2016). https://doi.org/10.1016/j.buildenv.2016.03.020

43. Keshtkar, A., Arzanpour, S., Keshtkar, F.: Adaptive residential demand-side management using rule-based techniques in smart grid environments. Energy Build. 133, 281-294 (2016). https:// doi.org/10.1016/j.enbuild.2016.09.070

44. Mehta, N., Sinitsyn, N.A., Backhaus, S., Lesieutre, B.C.: Safe control of thermostatically controlled loads with installed timers for demand side management. Energy Convers. Manag. 86, 784791 (2014). https://doi.org/10.1016/j.enconman.2014.06.049

45. Reynders, G., Nuytten, T., Saelens, D.: Potential of structural thermal mass for demand-side management in dwellings. Build. Environ. 64, 187-199 (2013). https://doi.org/10.1016/j.build env.2013.03.010

46. Kwok, T.F., Xu, Y., Wong, P.T.: Complying with voluntary energy conservation agreements (I): air conditioning in Hong Kong's shopping malls. Resour. Conserv. Recycl. 117, 213 224 (2017). https://doi.org/10.1016/j.resconrec.2016.10.014

47. Kwok, T.F., Xu, Y., Wong, P.T.: Complying with voluntary energy conservation agreements (II): lighting in Hong Kong's shopping malls. Resour. Conserv. Recycl. 117, 225-234 (2017). https://doi.org/10.1016/j.resconrec.2016.10.013

48. Zakeri, B., Lahdelma, R., Syri, S., Helin, K., Käki, A.: Economic potential of industrial demand side management in pulp and paper industry. Energy. 141, 1681-1694 (2017). https:// doi.org/10.1016/j.energy.2017.11.075

49. Paulus, M., Borggrefe, F.: The potential of demand-side management in energy-intensive industries for electricity markets in Germany. Appl. Energy 88, 432-441 (2011). https://doi. org/10.1016/j.apenergy.2010.03.017

50. Finn, P., Fitzpatrick, C.: Demand side management of industrial electricity consumption: promoting the use of renewable energy through real-time pricing. Appl. Energy 113, 11-21 (2014). https://doi.org/10.1016/j.apenergy.2013.07.003

51. Thakur, J., Chakraborty, B.: Demand side management in developing nations: a mitigating tool for energy imbalance and peak load management. Energy. 114, 895-912 (2016). https:// doi.org/10.1016/j.energy.2016.08.030

52. Harish, V.S.K.V., Kumar, A.: Demand side management in India: action plan, policies and regulations. Renew. Sustain. Energy Rev. 33, 613-624 (2014). https://doi.org/10.1016/j. rser.2014.02.021

53. Akinbulire, T.O., Oluseyi, P.O., Babatunde, O.M.: Technoeconomic and environmental evaluation of demand side management techniques for rural electrification in Ibadan, Nigeria. Int. J. Energy Environ. Eng. 5, 375-385 (2014). https://doi. org/10.1007/s40095-014-0132-2

54. Siddiqui, M.Z., de Maere d'Aertrycke, G., Smeers, Y.: Demand response in Indian electricity market. Energy Policy 50, 207216 (2012). https://doi.org/10.1016/j.enpol.2012.06.030

55. Ikpe, E., Torriti, J.: A means to an industrialisation end? Demand Side Management in Nigeria. Energy Policy. 115, 207-215 (2018). https://doi.org/10.1016/j.enpol.2018.01.011

56. Yang, M.: Demand side management in Nepal. Energy. 31, 2341-2362 (2006). https://doi.org/10.1016/j.energ y.2005.12.008

57. Yang, C.J.: Opportunities and barriers to demand response in China. Resour. Conserv. Recycl. 121, 51-55 (2017). https://doi. org/10.1016/j.resconrec.2015.11.015

58. Proença, L.C., Ghisi, E., Tavares, D.D.F., Coelho, G.M.: Potential for electricity savings by reducing potable water consumption in a city scale. Resour. Conserv. Recycl. 55, 960-965 (2011). https://doi.org/10.1016/j.resconrec.2011.05.003

59. IEA: Electricity Information (2017). http://www.iea.org. Accessed 30 Sept 2018

60. BPDB: Annual Report: 2016-2017, Dhaka (2017). http://www. bpdb.gov.bd/download/annual_report/AnnualReport2016-17(3). pdf. Accessed 29 Sept 2018

61. Khan, I.: Power generation expansion plan and sustainability in a developing country: a multi-criteria decision analysis. J. Clean. Prod. 220, 707-720 (2019). https://doi.org/10.1016/J.JCLEP RO.2019.02.161

62. EECMP: Energy Efficiency and Conservation Master Plan up to 2030, Dhaka (2015). http://sreda.gov.bd/files/EEC_Maste r_Plan_SREDA.pdf. Accessed 14 Sept 2018

63. Sharifi, R., Fathi, S.H., Vahidinasab, V.: A review on Demandside tools in electricity market. Renew. Sustain. Energy Rev. 72, 565-572 (2017). https://doi.org/10.1016/j.rser.2017.01.020

64. Nolan, S., O'Malley, M.: Challenges and barriers to demand response deployment and evaluation. Appl. Energy 152, 1-10 (2015). https://doi.org/10.1016/j.apenergy.2015.04.083

65. Good, N., Ellis, K.A., Mancarella, P.: Review and classification of barriers and enablers of demand response in the smart grid. Renew. Sustain. Energy Rev. 72, 57-72 (2017). https://doi. org/10.1016/j.rser.2017.01.043

66. Borg, S.P., Kelly, N.J.: The effect of appliance energy efficiency improvements on domestic electric loads in European households. Energy Build. 43, 2240-2250 (2011). https://doi. org/10.1016/j.enbuild.2011.05.001

67. EPRI: Principles and practice of Demand Side Management, Palo Alto, California (1993). https://www.epri.com/. Accessed 6 Oct 2018

68. Uddin, M., Romlie, M.F., Abdullah, M.F., Abd Halim, S., Abu Bakar, A.H., Chia Kwang, T.: A review on peak load shaving strategies. Renew. Sustain. Energy Rev 82, 3323-3332 (2018). https://doi.org/10.1016/j.rser.2017.10.056 
69. Torriti, J.: Peak energy demand and demand side response, 1 st edn. Routledge, New York (2016). https://doi.org/10.4324/97813 15781099

70. Aalami, H., Yousefi, G.R., Parsa Moghadam, M.: Demand response model considering EDRP and TOU programs. In: 2008 IEEE/PES Transm. Distrib. Conf. Expo., IEEE, 2008: pp. 1-6. https://doi.org/10.1109/tdc.2008.4517059

71. Newsham, G.R., Bowker, B.G.: The effect of utility time-varying pricing and load control strategies on residential summer peak electricity use: a review. Energy Policy. 38, 3289-3296 (2010). https://doi.org/10.1016/j.enpol.2010.01.027

72. Marwan, M., Kamel, F.: Demand side response to mitigate electrical peak demand in Eastern and Southern Australia. Energy Proc. 12, 133-142 (2011). https://doi.org/10.1016/j.egypr o.2011.10.019

73. FERC: Assessment of demand response and advanced metering (2006) https://www.smartgrid.gov/files/Northwest_Open_Autom ated_Demand_Response_Technology_Demonstr_200612.pdf. Accessed 11 Nov 2018

74. Taylor, B., Taylor, C.: Demand response: managing electric power peak load shortages with market mechanisms (2015). https ://www.raponline.org/. Accessed 17 Nov 2018

75. Bolívar Jaramillo, L., Weidlich, A.: Optimal microgrid scheduling with peak load reduction involving an electrolyzer and flexible loads. Appl. Energy. 169, 857-865 (2016). https://doi. org/10.1016/j.apenergy.2016.02.096

76. Song, L., Xiao, Y., Van Der Schaar, M.: Non-stationary demand side management method for smart grids. In: IEEE Int. Conf. Acoust. Speech Signal Process., IEEE, Florence, Italy, 2014: pp. 7759-7763. https://doi.org/10.1109/icassp.2014.6855110

77. Fernandes, F., Morais, H., Vale, Z., Ramos, C.: Dynamic load management in a smart home to participate in demand response events. Energy Build. 82, 592-906 (2014). https://doi. org/10.1016/j.enbuild.2014.07.067

78. Thein, T., Myo, M.M., Parvin, S., Gawanmeh, A.: Reinforcement learning based methodology for energy-efficient resource allocation in cloud data centers. J. King Saud Univ. Comput. Inf. Sci. (2018). https://doi.org/10.1016/j.jksuci.2018.11.005. (in press)

79. Jiang, B., Fei, Y.: Dynamic residential demand response and distributed generation management in smart microgrid with hierarchical agents. Energy Proc. 12, 76-90 (2011). https://doi. org/10.1016/j.egypro.2011.10.012

80. Marinescu, A., Dusparic, I., Clarke, S.: Prediction-based multiagent reinforcement learning in inherently non-stationary environments. ACM Trans. Auton. Adapt. Syst. 12, 1-23 (2017). https://doi.org/10.1145/3070861

81. Glavic, M., Fonteneau, R., Ernst, D.: Reinforcement learning for electric power system decision and control: past considerations and perspectives. IFAC-Pap Online. 50, 6918-6927 (2017). https ://doi.org/10.1016/j.ifacol.2017.08.1217

82. Dusparic, I., Taylor, A., Marinescu, A., Cahill, V., Clarke, S.: Maximizing renewable energy use with decentralized residential demand response. In: IEEE 1st Int. Smart Cities Conf., IEEE, Guadalajara, Mexico, 2015: pp. 1-6. https://doi.org/10.1109/ isc2.2015.7366212

83. Pina, A., Silva, C., Ferrão, P.: The impact of demand side management strategies in the penetration of renewable electricity. Energy. 41, 128-137 (2012). https://doi.org/10.1016/j.energ y.2011.06.013

84. Tascikaraoglu, A., Boynuegri, A.R., Uzunoglu, M.: A demand side management strategy based on forecasting of residential renewable sources: a smart home system in Turkey. Energy Build. 80, 309-320 (2014). https://doi.org/10.1016/j.enbui ld.2014.05.042
85. Aghaei, J., Alizadeh, M.I.: Demand response in smart electricity grids equipped with renewable energy sources: a review. Renew. Sustain. Energy Rev. 18, 64-72 (2013). https://doi.org/10.1016/j. rser.2012.09.019

86. Mesarić, P., Krajcar, S.: Home demand side management integrated with electric vehicles and renewable energy sources. Energy Build. 108, 1-9 (2015). https://doi.org/10.1016/j.enbui ld.2015.09.001

87. Nahiduzzaman, K.M., Aldosary, A.S., Abdallah, A.S., Asif, M., Kua, H.W., Alqadhib, A.M.: Households energy conservation in Saudi Arabia: lessons learnt from change-agents driven interventions program. J. Clean. Prod. 185, 998-1014 (2018). https://doi. org/10.1016/j.jclepro.2018.03.052

88. Han, Q., Nieuwenhijsen, I., de Vries, B., Blokhuis, E., Schaefer, W.: Intervention strategy to stimulate energy-saving behavior of local residents. Energy Policy. 52, 706-715 (2013). https://doi org/10.1016/j.enpol.2012.10.031

89. Karlin, B., Davis, N., Sanguinetti, A., Gamble, K., Kirkby, D., Stokols, D.: Dimensions of conservation: exploring differences among energy behaviors. Environ. Behav. 46, 423-452 (2012). https://doi.org/10.1177/0013916512467532

90. Nicholls, L., Strengers, Y.: Peak demand and the 'family peak' period in Australia: understanding practice (in)flexibility in households with children. Energy Res. Soc. Sci. 9, 116-124 (2015). https://doi.org/10.1016/j.erss.2015.08.018

91. Laicane, I., Blumberga, D., Blumberga, A., Rosa, M.: Reducing household electricity consumption through demand side management : the role of home appliance scheduling and peak load reduction. Energy Proc. 72, 222-229 (2015). https://doi. org/10.1016/j.egypro.2015.06.032

92. Powells, G., Bulkeley, H., Bell, S., Judson, E.: Peak electricity demand and the flexibility of everyday life. Geoforum 55, 43-52 (2014). https://doi.org/10.1016/j.geoforum.2014.04.014

93. Spees, K., Lave, L.: Impacts of responsive load in PJM : load shifting and real time pricing. Energy J. 29, 101-121 (2008). https://www.jstor.org/stable/41323159. Accessed 17 Nov 2018

94. Meyabadi, A.F., Deihimi, M.H.: A review of demand-side management: reconsidering theoretical framework. Renew. Sustain. Energy Rev. 80, 367-379 (2017). https://doi.org/10.1016/j. rser.2017.05.207

95. Behrangrad, M.: A review of demand side management business models in the electricity market. Renew. Sustain. Energy Rev. 47, 270-283 (2015). https://doi.org/10.1016/j.rser.2015.03.033

96. Darby, S.: The effectiveness of feedback on energy consumption (2006). http://www.eci.ox.ac.uk/research/energy/downloads/ smart-metering-report.pdf. Accessed 29 Sept 2018

97. Buchanan, K., Russo, R., Anderson, B.: Feeding back about eco-feedback: how do consumers use and respond to energy monitors? Energy Policy. 73, 138-146 (2014). https://doi. org/10.1016/j.enpol.2014.05.008

98. Du, L., Guo, J., Wei, C.: Impact of information feedback on residential electricity demand in China. Resour. Conserv. Recycl. 125, 324-334 (2017). https://doi.org/10.1016/j.resco nrec.2017.07.004

99. Karlin, B., Zinger, J.F., Ford, R.: The effects of feedback on energy conservation: a meta-analysis. Psychol. Bull. 141, 12051227 (2015). https://doi.org/10.1037/a0039650

100. Schultz, P.W., Estrada, M., Schmitt, J., Sokoloski, R., SilvaSend, N.: Using in-home displays to provide smart meter feedback about household electricity consumption: a randomized control trial comparing kilowatts, cost, and social norms. Energy. 90, 351-358 (2015). https://doi.org/10.1016/j.energ y.2015.06.130 
101. Becker, L.J.: Joint effect of feedback and goal setting on performance: a field study of residential energy conservation. J. Appl. Psychol. 63, 428-433 (1978). https://doi. org/10.1037/0021-9010.63.4.428

102. McCalley, L.T., Midden, C.J.H.: Energy conservation through product-integrated feedback: the roles of goal-setting and social orientation. J. Econ. Psychol. 23, 589-603 (2002). https://doi. org/10.1016/S0167-4870(02)00119-8

103. Martiskainen, M.: Affecting consumer behaviour on energy demand (2007). http://citeseerx.ist.psu.edu/viewdoc/download ?doi=10.1.1.463.7249\&rep=rep1\&type $=$ pdf. Accessed 22 Oct 2018

104. Gilbert, B., Graff Zivin, J.: Dynamic salience with intermittent billing: evidence from smart electricity meters (2013). http:// www.nber.org/papers/w19510. Accessed 22 Oct 2018

105. Mizobuchi, K., Takeuchi, K.: The influences of financial and non-financial factors on energy-saving behaviour: a field experiment in Japan. Energy Policy. 63, 775-787 (2013). https://doi. org/10.1016/j.enpol.2013.08.064

106. Fisher, J., Irvine, K.: Reducing household energy use and carbon emissions: the potential for promoting significant and durable changes through group participation. In: IESD PhD Conf. Energy Sustain. Dev., Leicester, pp. 49-57 (2010). http://www.iesd.dmu. ac.uk/events/phd_conference_2010/papers/Fisher.pdf. Accessed 30 Sept 2018

107. Allcott, H.: Social norms and energy conservation. J. Public Econ. 95, 1082-1095 (2011). https://doi.org/10.1016/j.jpube co.2011.03.003

108. Ayres, I., Raseman, S., Shih, A.: Evidence from two large field experiments that peer comparison feedback can reduce residential energy usage. J. Law. Econ. Organ. 29, 992-1022 (2013). https://doi.org/10.1093/jleo/ews020

109. Delmas, M.A., Fischlein, M., Asensio, O.I.: Information strategies and energy conservation behavior: a meta-analysis of experimental studies from 1975 to 2012. Energy Policy. 61(2013), 729-739 (2013). https://doi.org/10.1016/j.enpol.2013.05.109

110. Abrahamse, W., Steg, L.: Social influence approaches to encourage resource conservation: a meta-analysis. Glob. Environ. Chang. 23, 1773-1785 (2013). https://doi.org/10.1016/j.gloen vcha.2013.07.029

111. de la Rue du Can, S., McNeil, M., Letschert, V., Shen, B., Sathaye, J.: DSM Electricity Savings potential in the buildings sector in APP countries, Berkeley, CA, USA (2011). https:// www.osti.gov/servlets/purl/1011507. Accessed 17 Nov 2018

112. Asensio, O.I., Delmas, M.A.: Nonprice incentives and energy conservation. In: Proc. Natl. Acad. Sci. U. S. A. 112 (2015) E510-5. https://doi.org/10.1073/pnas.1401880112

113. Asensio, O.I., Delmas, M.A.: The dynamics of behavior change: evidence from energy conservation. J. Econ. Behav. Organ. 126, 196-212 (2016). https://doi.org/10.1016/j.jebo.2016.03.012

114. Allcott, H., Rogers, T.: The short-run and long-run effects of behavioral interventions: experiment evidence from energy conservation. Am. Econ. Rev. 104, 3003-3037 (2014). https://doi. org/10.1257/aer.104.10.3003

115. Khan, I.: Household factors and electrical peak demand : a review for further assessment. Adv. Build. Energy Res. (2019). https://doi.org/10.1080/17512549.2019.1575770

116. Besagni, G., Borgarello, M.: The determinants of residential energy expenditure in Italy. Energy. 165, 369-386 (2018). https ://doi.org/10.1016/j.energy.2018.09.108

117. Brounen, D., Kok, N., Quigley, J.M.: Residential energy use and conservation: economics and demographics. Eur. Econ. Rev. 56, 931-945 (2012). https://doi.org/10.1016/j.euroecorev .2012 .02 .007
118. Longhi, S.: Residential energy expenditures and the relevance of changes in household circumstances. Energy Econ. 49, 440-450 (2015). https://doi.org/10.1016/j.eneco.2015.03.018

119. Filippini, M., Pachauri, S.: Elasticities of electricity demand in urban Indian households. Energy Policy. 32, 429-436 (2004). https://doi.org/10.1016/S0301-4215(02)00314-2

120. Galvin, R., Sunikka-Blank, M.: Economic viability in thermal retrofit policies: learning from ten years of experience in Germany. Energy Policy. 54, 343-351 (2013). https://doi. org/10.1016/j.enpol.2012.11.044

121. Bhattacharjee, S., Reichard, G., McCoy, A., Pearce, A., Beliveau, Y.: Identification of elements to control and regulate residential energy consumption. Adv. Build. Energy Res. 8, 174-195 (2014). https://doi.org/10.1080/17512549.2013.865552

122. Monyei, C.G., Adewumi, A.O.: Demand side management potentials for mitigating energy poverty in South Africa. Energy Policy. 111, 298-311 (2017). https://doi.org/10.1016/j.enpol 2017.09.039

123. Monyei, C.G., Adewumi, A.O.: Integration of demand side and supply side energy management resources for optimal scheduling of demand response loads-South Africa in focus. Electr. Power Syst. Res. 158, 92-104 (2018). https://doi.org/10.1016/j. epsr.2017.12.033

124. Li, P.H., Pye, S.: Assessing the benefits of demand-side flexibility in residential and transport sectors from an integrated energy systems perspective. Appl. Energy 228, 965-979 (2018). https ://doi.org/10.1016/j.apenergy.2018.06.153

125. Yang, M., Rumsey, P.: Energy conservation in typical Asian countries. Energy Sources 19, 507-521 (1997). https://doi. org/10.1080/00908319708908868

126. Buchanan, K., Russo, R., Anderson, B.: The question of energy reduction: the problem(s) with feedback. Energy Policy. 77, 89-96 (2015). https://doi.org/10.1016/j.enpol.2014.12.008

127. Dietz, T., Gardner, G.T., Gilligan, J., Stern, P.C., Vandenbergh, M.P.: Household actions can provide a behavioral wedge to rapidly reduce US carbon emissions. Proc. Natl. Acad. Sci. 106, 18452-18456 (2009). https://doi.org/10.1073/pnas.0908738106

128. Attari, S.Z., DeKay, M.L., Davidson, C.I., Bruine de Bruin, W.: Public perceptions of energy consumption and savings. Proc. Natl. Acad. Sci. 107, 16054-16059 (2010). https://doi. org/10.1073/pnas.1001509107

129. Han, Q., Nieuwenhijsen, I., de Vries, B., Blokhuis, E., Schaefer, W.: Intervention strategy to simulate energy-saving behaviour of local residents. Energy Policy. 52, 706-715 (2013)

130. Kua, H.W., Wong, S.E.: Lessons for integrated household energy conservation policies from an intervention study in Singapore. Energy Policy. 47, 49-56 (2012). https://doi.org/10.1016/j.enpol .2012 .04 .009

131. Tilson, D.: Customer centric demand side management : five keys to increase customer adoption and create sustainable behavior (2015). https://www.westmonroepartners.com/. Accessed 30 Sept 2018

132. E.M. Rogers, Diffusion of innovations, 3rd ed., The Free Press, 1983

133. Xu, X., Culligan, P.J., Taylor, J.E.: Energy saving alignment strategy: achieving energy efficiency in urban buildings by matching occupant temperature preferences with a building's indoor thermal environment. Appl. Energy 123, 209-219 (2014). https ://doi.org/10.1016/j.apenergy.2014.02.039

134. Sorrell, S.: Mapping rebound effects from sustainable behaviours: key concepts and literature review, Guildford (2010). http://sustainablelifestyles.ac.uk/sites/default/files/publicatio nsdocs/slrg_working_paper_01-10.pdf. Accessed 29 Sept 2018 
135. Sorrell, S., Dimitropoulos, J., Sommerville, M.: Empirical estimates of the direct rebound effect: a review. Energy Policy. 37, 1356-1371 (2009). https://doi.org/10.1016/j.enpol.2008.11.026

136. Freire-González, J.: Evidence of direct and indirect rebound effect in households in EU-27 countries. Energy Policy. 102, 270-276 (2017). https://doi.org/10.1016/j.enpol.2016.12.002

137. Deng, G., Newton, P.: Assessing the impact of solar PV on domestic electricity consumption: exploring the prospect of rebound effects. Energy Policy. 110, 313-324 (2017). https:// doi.org/10.1016/j.enpol.2017.08.035

138. Thomas, B.A., Azevedo, I.L.: Estimating direct and indirect rebound effects for U.S. households with input-output analysis. Part 2: Simulation. Ecol. Econ. 86, 188-198 (2013). https://doi. org/10.1016/j.ecolecon.2012.12.002
139. Freire-González, J.: Methods to empirically estimate direct and indirect rebound effect of energy-saving technological changes in households. Ecol. Modell. 223, 32-40 (2011). https://doi. org/10.1016/j.ecolmodel.2011.09.001

140. Yu, B., Zhang, J., Fujiwara, A.: Evaluating the direct and indirect rebound effects in household energy consumption behavior: a case study of Beijing. Energy Policy. 57, 441-453 (2013). https ://doi.org/10.1016/j.enpol.2013.02.024

Publisher's Note Springer Nature remains neutral with regard to jurisdictional claims in published maps and institutional affiliations. 